\title{
European Clinical Specialization in Fluency Disorders (ECSF): Participants Review the First Four Years
}

\author{
Margaret Leahy \\ Trinity College \\ Dublin, Ireland \\ Joseph Agius \\ Univeristy of Malta \\ Msida, Malta \\ Carl Hylebos \\ Artevelde University College \\ Ghent, Belgium \\ Luc De Nil \\ University of Toronto \\ Toronto, Canada \\ University of Leuven \\ Leuven, Belgium

\section{Kurt Eggers} \\ Thomas More University College \\ Antwerp, Belgium \\ Disclosure: Financial: Margaret Leahy, Joseph Agius, Carl Hylebos, Luc De Nil, and Kurt Eggers \\ have no financial interests to disclose. \\ Nonfinancial: Margaret Leahy, Luc De Nil, and Kurt Eggers have previously published in this \\ topic. Some of these works are referenced in this paper. Joseph Agius and Carl Hylebos have no \\ nonfinancial interests to disclose.
}

\section{Abstract}

Background: The European Clinical Specialization in Fluency Disorders (ECSF) is a 1-year postgraduate course for speech and language therapists (known as speech-language pathologists in the United States). The program was developed by a consortium whose members are specialists in fluency disorders from European universities/colleges. The consortium expanded to include other EU college members and specialists from EU centers of clinical excellence.

Purpose: This paper presents an evaluative review by students and teachers who have participated in the initial 4 years of ECSF courses.

Methodology: Two mixed methods online survey questionnaire were used, one for each group (student course participants and consortium members, designated as teachers throughout the paper) with quantitative, comparative data gathering, along with elements of qualitative data emerging from invited comments, and from open-ended questions.

Results: High and relatively high levels of satisfaction were expressed by all participants regarding the overall experience of ECSF. There was a wider range of satisfaction expressed by student participants regarding aspects of course content and experience of clinical work. Participants' responses providing qualitative data indicate major influences of the ECSF on professional development, and strong appreciation of participation in ECSF. 
The European Clinical Specialization in Fluency Disorders (ECSF) is a unique 1-year program that provides highly structured opportunities for speech and language therapists (SLTs; known as speech-language pathologists in the United States) to develop competencies that lead towards specialist practitioner status in fluency disorders. Following a 2-year consultation and planning period, courses have been offered annually since 2008 (Eggers \& Leahy, 2011).

Initial meetings to develop the ECSF were held in 2006 in Lessius College (now Thomas More University College) in Antwerp, Belgium. The application made for funding to support course development via the European student mobility Erasmus/Socrates SLT network was accepted, and provided funding for meetings and discussion, leading to ECSF course development (Grant 28095-IC-1-2005-1-BE-Erasmus-Moduc-1). The rationale for developing the course was clear: recognition of the necessity for specialist education beyond undergraduate levels in fluency disorders had been longstanding (see Leahy, Delaney, \& Murphy, 2004; Sommers \& Caruso, 1995; Yaruss \& Quesal, 2002). Generally, in European colleges of education for undergraduate therapy students, students are introduced to the complex nature of fluency and disorders of fluency and provided with basic information regarding management principles. Despite the fact that approximately $1 \%$ of the general population stutters (Bloodstein $\&$ Bernstein Ratner, 2008), and that speech-language pathologists are likely to encounter people who stutter in their practice (Bernstein-Ratner $\&$ Tetnowski, 2006), many students graduate without ever having direct experience of working with a person with a fluency disorder (Leahy, Delaney, \& Murphy, 2004). The specialization course contributes substantially to the harmonization of professional standards of SLTs working in the field of fluency and fluency disorders in all participating countries, and its impact is expected to increase over time (Eggers, Leahy, De Nil, $\&$ Pertijs, 2010).

\section{The ECSF Consortium}

Members of the ECSF consortium are specialist therapists, researchers, and lecturers working in the area of fluency disorders, drawn from 13 universities and colleges in nine EU countries, along with two associate partners from Centres of Excellence for working with the people with fluency disorders. The countries represented in the consortium are: Belgium, Finland, Germany, Ireland, Malta, Netherlands, Portugal, the United Kingdom, and Sweden. Management of the consortium is led by the coordinator, whose responsibilities include representation of the consortium, general leadership, administration and coordination of committees and focus groups, and management of the financial affairs of the organization. The coordinator is based at Thomas More University College, Antwerp, Belgium, where student participants are registered. The coordinator is supported by two elected members of the consortium, forming the Steering Committee, whose responsibilities include planning and review of the courses, development and maintenance of course materials, decision-making regarding aspects of course management, and problem-solving. This committee meets four times during the year and is in regular contact through e-mail and telephone. In addition to providing education courses, the ECSF also organizes international symposia on a biannual basis (see www.ECSF.eu for details).

All members of the consortium participate as members of the general committee, which meets annually to review and discuss development. Focus groups concerned with specific aspects of the course (phenomenology, diagnostics; treatment) are drawn from the general committee. Committee members also support the course's student participants in the roles of mentoring clinical work, and coaching with regard to academic and clinical reflective learning.

\section{Student Course Participants}

ECSF course requirements are that participants are qualified SLTs, having at least a degree in the area of speech-language therapy (pathology) or its equivalent. To date, the majority 
of course participants are from European countries, with small numbers from the pan-Asian area, including Taiwan and Sri Lanka, with one graduate from Nigeria.

\section{Course Structure}

Overall, the weighting of the ECSF course currently represents 20 credits (ECTS; will be upgraded to 25 ECTS), where each credit is worth 25-30 hours of student work, as designated by the European Credit Transfer and Accumulation System: (http://ec.europa.eu/education/ lifelong-learning-policy/ects_en.htm). These credits are expressed in terms of learning outcomes. Teaching and learning of course content is structured to involve traditional lectures, small group discussion and project work, written assignments, one-to-one coaching, and individual study and reflection. The clinical component, which covers 120 hours of student time, takes place in a location of individual student's choice, under supervision of an experienced therapist (recognized and supported by the ECSF). The intensive part of the traditional teaching element occurs during 2 weeks of the year, 1 week in spring and 1 in autumn, in two EU locations. All participants are required to attend both intensive weeks. Along with academic written and practical clinical skills development, student participants' oral skills are developed through case study presentations. Group discussion and evaluation allow for the exchange of views regarding all aspects of the work presented, and aims to support a positive experience.

The huge scope of the field of fluency disorders provides the basis for the academic and clinical coursework covered during the ECSF. The topic range spans the spectrum from phenomenology and aetiological factors, through the diagnostic and management processes, with reference to evidence bases, evaluating outcomes and producing evidence. Participants engage in a range of learning experiences that include traditional lectures, open discussion, one-to-one mentoring and coaching, small group assignments, personal research, and presentation work. The opportunity to apply knowledge to practice is provided through participation in specialist clinical experience, under supervision of experienced clinicians or mentors. Mentoring involves a relationship where a senior professional takes a junior professional "under his or her wing" and provides guidance and counsel. The focus is on the process of learning in a "safe" context. The mentor helps the participant to enhance assessment and intervention competencies, and may also assist in providing clinical observation (20 hours maximum). In the case of coaching, and ECSF-coach helps participants to develop and enhance self-reflection competency, gives advice and guidance in the process of developing the portfolio, and is the portfolio assessor. Where necessary, contact with mentors and coaches is facilitated via Skype calls and participants may provide supervisors with clinical videos for discussion and evaluation.

An aspect of the ECSF that encourages participation and the acquisition of knowledge, attitudes and skills is the high motivation of all involved to engage with people, promoting enthusiasm about the topics discussed. There is openness towards discussion and feedback at all levels. The course provides an extra dimension by creating a sphere of exchange and integration among the participating students and teachers, influencing both parties positively. The atmosphere created within the year groups tends towards a spirit of fun and enjoyment, along with supportive helpfulness.

Since its institution, the ECSF consortium has organized and delivered annual courses, along with biannual international symposia. At the time of data collection for this review (2011-12), three annual courses had been completed, with 42 graduates practicing as fluency clinicians, and 21 participants scheduled to graduate at the end of academic year (September, 2012).

\section{Rationale for the Study}

The ECSF is an international enterprise with a unique composition addressing the need for specialist education and practice in the area of fluency disorders. A review of the ECSF 
provides the opportunity for all participants to give feedback regarding their experiences of course management and implementation and to suggest changes. Ultimately, the review serves to improve course planning and participation.

\section{Methodology}

The course review adopted a mixed method online survey questionnaire design, using SurveyMonkey (SurveyMonkey.com). There were two questionnaires, one for student/graduate participants and one for consortium members/teachers. The questionnaires used primarily quantitative and comparative approaches, with elements of qualitative data emerging from open-ended questions and invited comments included following the questions requesting satisfaction (or other) ratings, and from an additional open-ended question, prompted during discussion of the survey results at an international conference (see Appendix 1 for sample of questionnaire items).

\section{Participants}

All ECSF graduates and those attending the 2011-12 course were invited to respond to the survey. All of the participating members of teaching staff were invited to participate to a separate survey. The invitations were circulated via e-mail by the secretary of the ECSF to ensure anonymity and reduce direct contact between students and teachers.

Of the graduates $(n=42)$ and students $(n=21)$, responses were received from 37 individuals, representing a 59\% response rate. Of the 15 possible respondents who are partners/teachers in the consortium, 14 participated in an additional survey (93.3\%). Nine of the partners (64.3\%) had been involved with ECSF for the 6 years since its beginning.

\section{Questionnaires}

The student questionnaire was divided into 3 main parts, posing 15 questions, and took approximately 12 minutes to complete. Quantitative data was collected providing information regarding demographics of participants and feedback regarding the course by indicating satisfaction ratings about course content, delivery, and experience of participation.

Statistical data analysis was completed by the SurveyMonkey package, providing percentages of levels of satisfaction and comparative statistics regarding different levels of satisfaction ratings.

\section{Qualitative Data}

The use of open-ended questions (e.g., regarding motivation to participate in ECSF and regarding suggested changes) and an invitation to comment on the areas requesting rating responses provided qualitative data in the survey. Motivation and suggested changes are reported separately, and examples of invited comments are presented following reportage of satisfaction ratings. An additional open-ended question to indicate professional development as result of ECSF was prompted by Dr. Jennifer Watson, vice president for Standards and Ethics at the American Speech-Language-Hearing Association, at the time the paper was presented at the International Fluency Association Congress in July 2012. The question was circulated by e-mail from the ECSF secretary, with a request to respond to her e-mail address; the secretary compiled the responses, removing all identification data, and forwarded this compilation to the first author. This data was analyzed qualitatively, following immersion in the data that required re-reading it several times to become familiar with the emerging themes, and arranging related themes under clusters (Braun \& Clarke, 2006). The question that was circulated to all graduates ( $n=42)$ was: How has your experience in and graduation from the ECSF course influenced or altered your own professional life, practice and development?

The teachers' questionnaire sought information regarding their experience of ECSF; team involvement and consultation; and cost effectiveness of the course. 


\section{Results}

The overall experience of course participants of the ECSF indicated a high (95\%) satisfaction rating, within the range from very satisfactory to moderately satisfactory.

Motivations to participate in the ECSF (see Appendix 1 for open question posed) included special interest in the topic of stuttering and motivation to learn more to broaden expertise in working in fluency disorders and to participate in supervised clinical work. International perspectives proved attractive for some, with opportunity to obtain different perspectives on fluency. In addition, course structure and organization-2 intensive weeks of teaching and participation in local specialist clinical work during the year, with home-based study-proved attractive because of its ease of management.

\section{Students' Evaluation of Course Content and Delivery}

- $\quad$ Range of Topics covered was rated as very satisfactory $(94 \%)$

- Depth of Coursework was rated as very satisfactory or satisfactory (93\%)

- Evaluation of Teaching/lecturing was rated very satisfactory or satisfactory (93\%)

- Responses to invited comments indicated more time was needed for certain topics

- Number of Assignments was rated very satisfactory (49\%) or satisfactory (51\%)

- Depth of Assignments was rated very satisfactory (22\%); or satisfactory (72\%)

- Range: rated as very satisfactory or satisfactory $(77 \%)$

- Range and Depth of Assignments rated as Unsatisfactory (16\%)

- Hours was rated as satisfactory $(91 \%)$

- Supervision was rated as very satisfactory or satisfactory (72\%)

- Coaching was rated as very satisfactory or satisfactory $(88 \%)$

- Mentoring was rated as very satisfactory or satisfactory $(89 \%)$

- Timing of course was rated as very satisfactory (86\%)

- Location of the course was rated as very satisfactory $(84 \%)$

- Numbers participating in the course was rated as 'Just right' (92\%)

- Use of Blackboard was rated as very satisfactory or satisfactory (80\%)

Students' comments included: "I felt privileged to be part of the course," "I feel full of ideas and ambitions to learn more," "very invigorating and challenging," "really interesting, it allows to study new theoretical knowledge," "meet very prepared SLTs from all of world," and "truly enjoyed the course, many teachers, different style of teaching and travelling."

\section{Students' Suggestions for Changes}

Responses in this section focused on increasing time spent for teaching/learning and reducing the intensity of teaching/learning during the intensive weeks. A small number of students indicated that introducing a third intensive week, with less intensity, would be a positive development (however, a further week would impact negatively on course registration fees). Students also indicated a preference for more workshops, providing practical casework, and more time for discussion and interchange during the intensive weeks. More opportunities to meet with coaches and more alliances with International Centres of Excellence for stuttering therapy were also recorded. Increasing teaching on the topic of dual diagnosis was also suggested, along with an increase in role-play demonstrating best practice. 
The additional question regarding ECSF influences on professional life, practice and development was responded to by 9 graduates. The emerging themes (Braun \& Clarke, 2006), from the data were arranged into clusters of themes, under four main headings.

Positive professional learning experiences. Respondents mentioned themes regarding acquisition of skills, competencies, improved therapeutic knowledge.

Comments included: 'I feel like a better therapist now," "I'm more sure about what I can do to help clients," "I have a better idea of what to do in therapy," "the way of teaching helped me to understand principles of practice," "new and recent theoretical and practice specific knowledge in fluency," "I am now able to create more diverse and creative activities for each client," and "my practice is more in-depth and holistic."

Networking with international colleagues. Themes included meeting interesting people, the benefits of working with others, passion for working in fluency, and networking with ECSF colleagues.

Comments included: "I met interesting and wonderful people $[\ldots]$ with great passion for their job [...]," "contact with international experts injected enthusiasm and passion into my practice," "thanks to the ECSF and all the people I met, I love my work even more," "I use a lot more networking," and "if I have doubts, I know that I can ask some of my group, or some of my teachers."

Professional development. Themes included eagerness to continue learning, working in academia, increasing work in research, and working towards new qualifications.

Comments included: "this year, I teach a class at the university of [...]," "it has emphasized the need for further reading in pursuit of evidence," "it dragged me out of the clinic into research part time," "I want to learn more and more about stuttering," "I'm encouraged to work more on education, with more tools to be conscious about research," "a career in lecturing, but also on research," and "I am eager to learn more and to develop myself."

Increase in personal confidence, self-esteem. Themes emerged regarding growth in learning leading to growth in confidence.

Comments: "I gained more self-esteem and confidence," "I'm really happy about it," "an incredible experience that helped me grow personally and professionally," and "as result of ECSF, I have the confidence [...] and presented papers at international conferences, and submitted papers for publication."

\section{Partner/Teacher Survey}

Members of the ECSF Consortium, including those engaged in teaching, were asked to respond to a set of questions rating their satisfaction with a range of topics, including Experience of ECSF, Team Involvement, Team Consultation, and Cost Effectiveness. Their responses were uniformly positive overall, with $100 \%$ indicating ratings for all topics in the very satisfactory or satisfactory ranges.

Comments included "Astonishing[ ... I I can only recommend," "it's a challenge working with ECSF students," "great pleasure," and "rewarding for yourself as a lecturer/coach."

\section{Discussion}

Overall, responses of the majority of both groups (students/graduates \& partners / teachers) show that they were positive and enthusiastic about the experience of participation in ECSF. The response rate from the initial survey of students/graduates at 59\% was higher than average for such surveys (Baruch \& Holton, 2008) and the response rate for teachers was extremely high at $93 \%$. Whilst the high rate of response from students/graduates suggests enthusiastic and positive reactions to participation, it has to be viewed in the light of possible 
bias: the relatively small numbers involved in ECSF coursework provides the opportunity for teachers and students to work closely together, and this may have influenced responses in reducing negative inferences. However, efforts were made to reduce possible bias, in that no direct contact between teachers and students/graduates was made in circulating the survey, and the survey was anonymous, questions were posed neutrally, and the opportunity to provide negative responses was equal to the opportunity to provide positive responses. The range of responses regarding clinical experiences and range and depth of elements covered provides "unsatisfactory" rating up to $16 \%$. While this finding indicates a source of concern for consortium members, it demonstrates the freedom of participants to feedback regarding negative aspects of the course, suggesting that bias is not strong, across the board.

The open-ended question posed following the initial survey was responded to by a small number $(n=9)$ who were uniformly positive about the ECSF experience, and provided a small amount of rich data that included the value of ECSF in supporting professional competencies and personal confidence, but also in stimulating learning and research, and in networking with international colleagues.

\section{Conclusion}

The European Clinical Specialization in Fluency Disorders is a welcome, cost-effective development in the world of post-graduate education for speech and language pathologists. Special characteristics include the highly motivated graduate students from a wide range of countries, who participate with eagerness to learn and to grow professionally. Based on their feedback, course improvements have been implemented that include practical course changes, and the organization of an annual ECSF graduate workshop, held parallel to the first intensive week of the course. The uniformly positive responses from consortium members demonstrate the successful international partnership of cooperation for organization, teaching and clinical work.

\section{References}

Baruch, Y., \& Holtom, B. (2008). Survey response rate levels and trends in organizational research. Human Relations, 61, 1139-1160.

Bernstein-Ratner, N., \& Tetnowski, J. (2006). Stuttering treatment in the new millennium: Changes in the traditional focus. In N. Bernstein-Ratner, N., \& J. Tetnowski (Eds), Current issues in stuttering research \& practice. Mahwah, NJ: Lawrence Erlbaum.

Bloodstein, O., \& Bernstein Ratner, N. (2008). A handbook of stuttering. New York, NY: Delmar.

Braun, V., \& Clarke, V. (2006). Using thematic analysis in psychology. Qualitative Research in Psychology, 3, 77-101.

Eggers, K., \& Leahy, M. (2011). The European Clinical Specialization on Fluency Disorders (ECSF). Journal of Fluency Disorders, 36, 296-301.

Eggers, K., Leahy, M., De Nil, L., \& Pertijs, M. (2010, November). Working towards minimal standards for European fluency specialists. Poster presented at the annual convention of the American Speech-Language-Hearing Association, Philadelphia.

Leahy, M., Delaney, C., \& Murphy, K. (2004). Student clinicians' preferences for (not) working with stuttering. In Proceedings of IFA 4th World Congress, (pp. 539-545). Nijmegen, Netherlands: Nijmegen University Press.

Sommers, R. K., \& Caruso, A. (1995). Inservice training in speech-language pathology: Are we meeting the needs for training? American Journal of Speech-Language Pathology, 4, 22-28.

Yaruss, J. S., \& Quesal, R. (2002). Academic and clinical education in fluency disorders: An update. Journal of Fluency Disorders 27, 43-63. 